\title{
PALESTINA PARTIDA: OS BANTUSTÕES DE ISRAEL UM ESTUDO COMPARATIVO ENTRE AS NORMAS INSTITUCIONAIS DE SEGREGAÇÃO NOS TERRITÓRIOS PALESTINOS E NA ÁFRICA DO SUL DO APARTHEID.
}

\author{
Guilherme Morgensztern Russo ${ }^{1}$
}

\section{TORN PALESTINE: ISRAEL'S BANTUSTANS \\ A COMPARATIVE STUDY BETWEEN THE INSTITUTIONAL NORMS OF SEGREGATION IN THE PALESTINIAN TERRITORIES AND SOUTH AFRICA DURING THE APARTHEID.}

\begin{abstract}
Resumo: Por meio de comparações entre as normas que estabeleceram e regeram os bantustões sulafricanos e as que regulam os Territórios Palestinos - e seus processos de formação, dinâmicas sociais e econômicas - este artigo pretende aferir fundamentos das críticas que qualificam o governo de Israel como um regime de apartheid.
\end{abstract}

Palavras-chave: Apartheid, Israel, Territórios Palestinos, segregação, racismo, África do Sul, Bantustões.
Abstract: By comparing the norms that established and guided the South-African Bantustans, and those that regulate the Palestinian Territories and their processes of formation and dynamics, both social and economic - this article intends to verify the substance of critics that qualify the Israeli government as an apartheid regime.

Keywords: Apartheid, Israel, Palestinian Territories, segregation, racism, South Africa, Bantustans.

\section{INTRODUÇÃo}

Apesar do recente aceno dado pelo premiê de Israel, Binyamin Netanyahu, ao seu homólogo britânico, David Cameron, de que pretende "retomar negociações diretas com os palestinos, sem nenhum tipo de condição (...) imediatamente"2, ainda parece improvável que um processo de paz entre israelenses e palestinos ponha fim na ocupação de Israel à Cisjordânia e Jerusalém Oriental ou no bloqueio à Faixa de Gaza - territórios invadidos por Israel em 1967, durante a Guerra dos Seis Dias. Os assentamentos coloniais israelenses, assim como suas forças armadas, foram retirados de Gaza em 12 de setembro de 2005, após 38 anos de ocupação, mas o cerco ao território continuou, e o governo israelense impõe o bloqueio - com colaboração do governo egípcio, que também restringe sua fronteira - desde 2007, após o grupo fundamentalista islâmico Hamas ter assumido o poder no enclave palestino, sob a justificativa de conter os radicais ${ }^{3}$.

\footnotetext{
1 Jornalista formado pela PUC-SP, atuou entre 2010 e 2015 como repórter e editor-assistente de Internacional nos veículos impressos e online do grupo de comunicação 'O Estado de S.Paulo'. Esta pesquisa foi desenvolvida na Fundação Getulio Vargas, como trabalho de conclusão do MBA em Relações Internacionais da instituição. O artigo foi finalizado em setembro de 2015. Currículo lattes: http://buscatextual.cnpq.br/buscatextual/visualizacv.do?id=K8971926Z7. E-mail: guirusso@gmail.com

${ }^{2}$ BBC News - 10 set. 2015 - http://www.bbc.com/news/uk-34206350

${ }^{3}$ Após vencer as eleições legislativas palestinas, em janeiro de 2006, o Hamas travou um breve confronto
} 
A quebra de contiguidade territorial imposta pelos assentamentos israelenses nos Territórios Palestinos, o cerco da Faixa de Gaza e de localidades na Cisjordânia e a separação de Jerusalém Oriental por barreiras, muros, postos de controle e estradas segregadas, isolando os árabes em seus povoamentos e dificultando sua circulação, são os motivos mais evidentes que podem justificar a associação dos Territórios Palestinos aos bantustões sul-africanos. A comparação é frequentemente utilizada por analistas independentes ou críticos da política de ocupação praticada por Israel há quase 50 anos, enquanto o governo israelense é comparado ao regime do apartheid sul-africano.

Com base na política do desenvolvimento separado, o governo da África do Sul criou dez bantustões, também chamados de "homelands", entre 1951 e 1970, com o objetivo de separar os negros, segundo sua etnia ou tribo, da população branca ${ }^{4}$. Mas a restrição à residência de negros no território sul-africano existia desde o início do século 20. "Já em 1913, a população negra nativa tinha autorização para residir em apenas 13\% do país, em reservas demarcadas pelo governo colonial ${ }^{5 "}$, ressaltou a cientista política Leila Farsakh no estudo comparativo entre os bantustões e os Territórios Palestinos intitulado What Future for Palestine: Independence or Bantustans, de 2005.

Os bantustões duraram o quanto durou o apartheid: até 1994. "Dez homelands foram criadas para livrar a África do Sul de seus cidadãos negros, abrindo caminho para remoções forçadas em massa", informa o Museu do Apartheid ${ }^{6}$. 0 deslocamento forçado da população palestina que vivia no território conquistado pelas forças sionistas após a fundação de Israel, em 14 de maio de 19487 , também é apontado como um dos principais elementos de semelhança entre a formação populacional dos Territórios Palestinos e dos bantustões na África do Sul, já que negros foram agrupados nos enclaves determinados por Pretória ${ }^{8}$. Também em 1948, em 4 de junho, Daniel François Malan tornou-se premiê sul-africano, marcando o início do apartheid. As razões para as comparações entre os Territórios Palestinos e os bantustões, porém, não param por aí.

A "bantustização" dos Territórios Palestinos amalgamou-se após o fracasso dos Acordos de Oslo, de 1993, quando diferentes níveis de autonomia foram concedidos aos povoamentos da Cisjordânia ${ }^{9}$. Como o processo não resultou na fundação de um

com o Fatah, a facção palestina laica que ficou em segundo lugar na votação, e expulsou os rivais de Gaza, assumindo o governo do território. BBC News - Profile: Hamas Palestinian Movement - http://www.bbc. com/news/world-middle-east-13331522

${ }^{4}$ FARSAKH, Leila. What Future for Palestine: Independence or Bantustans. The Discourse of Sociological Practice, 7, 1/2, Spring/Fall 2005, p. 49.

5 idem.

${ }^{6}$ Museu do Apartheid - http://www.apartheidmuseum.org/homelands

${ }^{7}$ SHLAIM, Avi. Israel and Palestine: Reapprisals, Revisions, Refutations, cap. 4. London/New York: Verso, 2010.

${ }^{8}$ BEINART, William. Twentieth Century South Africa, cap. 6. Oxford: Oxford University Press, 2001.

${ }^{9}$ SHLAIM, Avi, op. cit., cap. 16. 
estado palestino independente, como estava previsto, a situação provisória - e oficial de administração de uma população de um território estrangeiro ocupado, por parte de Israel, perpetua-se. Quatro bantustões "aceitaram a independência"10, enquanto os outros seis "se tornaram 'estados nacionais' dentro da África do Sul"11. "Isso serviu como uma justificativa para negar a todos os africanos direitos políticos na África do Sul”, observa o Museu do Apartheid ${ }^{12}$, já que os negros, em vez de formar a população sul-africana, passaram a ser considerados estrangeiros por Pretória, simplesmente. Os diferentes níveis de autonomia entre as localidades palestinas e os bantustões também são fruto de comparações frequentes.

Uma semana antes das últimas eleições legislativas israelenses, ocorridas em 17 de março de 2015, o jornalista e analista político Ben White ressaltava em um artigo publicado no Middle East Monitor que o tratamento dos Territórios Palestinos como bantustões, por parte de Israel, continuaria mesmo se Netanyahu perdesse. 0 premiê afirmara dias antes que, caso reeleito, não promoveria "concessões nem retiradas" nos Territórios Palestinos. E White mostrava o posicionamento sobre o tema da União Sionista, aliança liderada por Isaac Herzog, do Partido Trabalhista, e Tzipi Livni, do Hatnuah, em segundo lugar nas pesquisas:

Desmilitarização do estado palestino, mantendo os blocos de assentamento na Judeia e em Samaria (a Cisjordânia) sob soberania israelense; fortalecimento de Jerusalém e seu status como a eterna capital do Estado de Israel e garantia de liberdade religiosa e acesso a locais sagrados a todas as religiões, juntamente com a manutenção da soberania de Israel. ${ }^{13}$

O Likud de Netanyahu ganhou por pouco, e o premiê quase não consegue formar coalizão para governar, mas, mesmo se o segundo colocado se saísse vencedor, a bantustização dos Territórios Palestinos continuaria.

Desta maneira, o mapa final do 'estado' palestino na visão da União Sionista é similar ao tipo de bantustão proposto por outro ex-líder trabalhista, Ehud Barak (que foi premiê entre julho de 1999 e março de 2001 e liderou a legenda até 2011, antes de fundar a União Sionista), com as fronteiras agora moldadas pelo Muro do Apartheid e a colonização israelense adicional do Vale do Jordão. ${ }^{14}$

Portanto - e mais -, o status dos Territórios Palestinos tende a continuar similar ao dos bantustões sul-africanos mesmo com a eventual independência da Palestina, pois sua soberania, recortada por assentamentos coloniais e cercada por concreto e arame farpado, estaria submetida à vontade de Israel - com suas constantes preocupações relativas a segurança e ameaças à sua sobrevivência.

\footnotetext{
${ }^{10}$ BEINART, William, op. cit., p. 223.

11 idem.

${ }^{12}$ Museu do Apartheid - http://www.apartheidmuseum.org/homelands

${ }^{13}$ WHITE, Ben. The Zionist Union's Plan for a Palestinian Bantustan. Middle East Monitor, 10 mar. 2015 https://www.middleeastmonitor.com/news/middle-east/17436-the-zionist-unions-plan-for-a-palestinian-bantustan

14 idem.
} 
artigo

\title{
METODOLOGIA
}

O historiador francês Marc Bloch definiu o campo da História Comparada como:

\begin{abstract}
Estudar paralelamente sociedades ao mesmo tempo vizinhas e contemporâneas, constantementeinfluenciadasumas pelas outras, sujeitas em seu desenvolvimento, devido à sua proximidade e à sua sincronização, à ação das mesmas grandes causas e remontando, ao menos parcialmente, a uma origem comum. ${ }^{15}$
\end{abstract}

A proposta deste artigo é justamente a análise paralela dos Territórios Palestinos e dos bantustões sul-africanos. A proximidade e a sincronização entre o governo israelense e o regime do apartheid ficarão evidentes após a comparação, durante a exposição das relações diplomáticas, comerciais e militares - incluindo na esfera nuclear - mantidas entre Israel e Pretória, o que ocorreu principalmente entre 1976 e $1994^{16}$. Remontar a uma possível origem comum - a que Bloch também se refere no trecho citado - entre as políticas de Israel e do apartheid, porém, seria objeto de um trabalho de campo aprofundado. Apesar disso, as semelhanças entre os regimes não deixam de ser gritantes.

Para Bloch, o método comparativo pressupunha determinados procedimentos, começando pela escolha do objeto. Deviam ser escolhidos dois ou mais fenômenos que pareciam, à primeira vista, guardar certas analogias entre si, em um ou vários meios sociais diferentes; em seguida, descrever as curvas de sua evolução, constatar as semelhanças e as diferenças e, na medida do possível, explicá-las sob a luz da aproximação uns dos outros. Propunha, de preferência, estudar paralelamente sociedades vizinhas e contemporâneas, sociedades sincrônicas, próximas umas das outras no espaço. ${ }^{17}$

Além de comum entre os críticos das políticas israelenses em relação aos árabes da Cisjordânia e da Faixa de Gaza, a comparação entre os Territórios Palestinos e os bantustões sul-africanos já foi feita por acadêmicos respeitados. Na comparação proposta para este artigo, citarei principalmente os estudos What Future for Palestine: Independence or Bantustans - já citado -, da cientista política Leila Farsakh, jordaniana de origem palestina, professora da Universidade de Massachusetts, PhD pela Universidade de Londres; e The Constitution of State/Space and the Limits of 'Autonomy' in South Africa and Palestine/ Israel, do sociólogo Andy Clarno, professor-assistente do Departamento de Sociologia da Universidade de Illinois, PhD pela Universidade de Michigan.

\section{AS COMPARAÇÕES}

A análise da bantustização dos Territórios Palestinos pode ser dividida em três fases principais: de 1948 a 1966, entre a fundação de Israel e os preâmbulos da Guerra dos

${ }^{15}$ BLOCH, Marc. Mélanges historiques: Pour une histoire comparée des sociétés européennes. Paris, CNRS Editions, 1963.

${ }^{16}$ POLAKOW-SURANSKY, Sasha. The Unspoken Alliance: Israel's Secret Relationship with Apartheid South Africa. New York: Vintage Books, 2010.

${ }^{17}$ PRADO, Maria Lígia Coelho. América Latina: Historia Comparada, Historias Conectadas, Historia Transnacional. Anuario Digital no 24, Escuela de Historia, Universidad Nacional de Rosario, 2012. 
Seis Dias; de 1967 a 1993, com a ocupação de Jerusalém Oriental, Cisjordânia e Faixa de Gaza por parte do governo israelense, que passou a administrar os enclaves; e de 1993 até agora, após os Acordos de Oslo terem criado a Autoridade Nacional Palestina e concedido autonomia ao organismo para sua autogestão e administração, em diferentes níveis, dos Territórios Palestinos ${ }^{18}$. A construção dos muros de separação - em torno de Gaza, a partir de 1994, e cercando povoamentos palestinos da Cisjordânia, desde 2002 - e as sucessivas e malsucedidas tentativas de negociação entre Israel e os palestinos após o fracasso de Oslo, entre 2000 e 2014, aprofundaram o processo ${ }^{19}$.

\section{NEGROS E PALESTINOS: ESPAÇOS, POPULAÇÕES E SOBERANIAS}

"Instituições e territórios separados para os negros; segregação espacial nas cidades e no campo; controle do movimento de africanos para as cidades ${ }^{20 "}$ estavam entre os "sete pilares" da política do Partido Nacional da África do Sul, que instituiu o apartheid no país enquanto esteve no poder, entre 1948 e 1994. Assim como os Acordos de Oslo estabeleceram três tipos de zonas administrativas nos Territórios Palestinos - "área A ficou sob controle exclusivo palestino, área $\mathrm{C}$ sob controle exclusivo israelense e, na área $\mathrm{B}$, os palestinos exercem a autoridade civil, enquanto Israel continua responsável pela segurança $a^{21 " ~-, ~ o ~ g o v e r n o ~ s u l-a f r i c a n o ~ t a m b e ́ m ~ c o n t o u ~ c o m ~ u m ~ a p a r a t o ~ l e g i s l a t i v o ~ p a r a ~}$ a criação dos bantustões. Em 1950, o Population Registration Act tornou obrigatória na África do Sul a classificação por raça da população do país ${ }^{22}$. No mesmo ano, o Group Areas Act e, em 1951, o Prevention of Ilegal Squatting Act permitiram "que as zonas raciais fossem criadas e que pessoas fossem deslocadas entre elas ${ }^{23 "}$ " Já o Bantu Authorities Act, também de 1951, concedeu autoridade a líderes tribais, para o "autogoverno" de suas reservas populacionais.

O estudo Heart of Hope - do "peacemaker" Padraig O’Maley, especialista em sociedades divididas e professor da Universidade de Massachusetts - cruza dados do South African Institute of Race Relations, de 1986, e uma compilação de estimativas de sensos sul-africanos de 1985 mostrando que, em meados da década de 1980, pouco mais de 39\% dos negros da África do Sul viviam nas "homelands" - o que equivale a mais de

\footnotetext{
${ }^{18}$ FARSAKH, Leila. What Future for Palestine: Independence or Bantustans. The Discourse of Sociological Practice, 7, 1/2, Spring/Fall 2005, p. 47-60.

${ }^{19}$ CLARNO, Andy. The Constitution of State/Space and the Limits of 'Autonomy' in South Africa and Palestine/Israel. Conference Papers, American Sociological Association, 2008.

BBC News - History of Mid-East Peace Talks - http://www.bbc.com/news/world-middle-east-11103745 BBC News - 10 set. 2015 - http://www.bbc.com/news/uk-34206350

${ }^{20}$ BEINART, William. Twentieth Century South Africa, cap. 6, p. 148. Oxford, Oxford University Press, 2001.

${ }^{21}$ SHLAIM, Avi. Israel and Palestine: Reapprisals, Revisions, Refutations, cap. 16, p. 202. London/New York: Verso, 2010.

${ }^{22}$ BEINART, William. Twentieth Century South Africa, cap. 6, p. 148. Oxford: Oxford University Press, 2001.

${ }^{23}$ ibidem, p. 153.
} 
9,7 milhões de pessoas ${ }^{24}$. Outras estimativas afirmam que até $60 \%$ ou $80 \%$ da população negra sul-africana viveria nos bantustões na época, mas sem demonstrar as hipóteses com números. Já nos Territórios Palestinos, vivem mais de 4,8 milhões de pessoas: 2,8 milhões na Cisjordânia, 1,8 milhão em Gaza e 209 mil em Jerusalém Oriental ${ }^{25}$.

A área ocupada pelos bantustões da África do Sul equivalia a 13\% do território do país ${ }^{26}$, quase $159.000 \mathrm{~km}^{2}$.

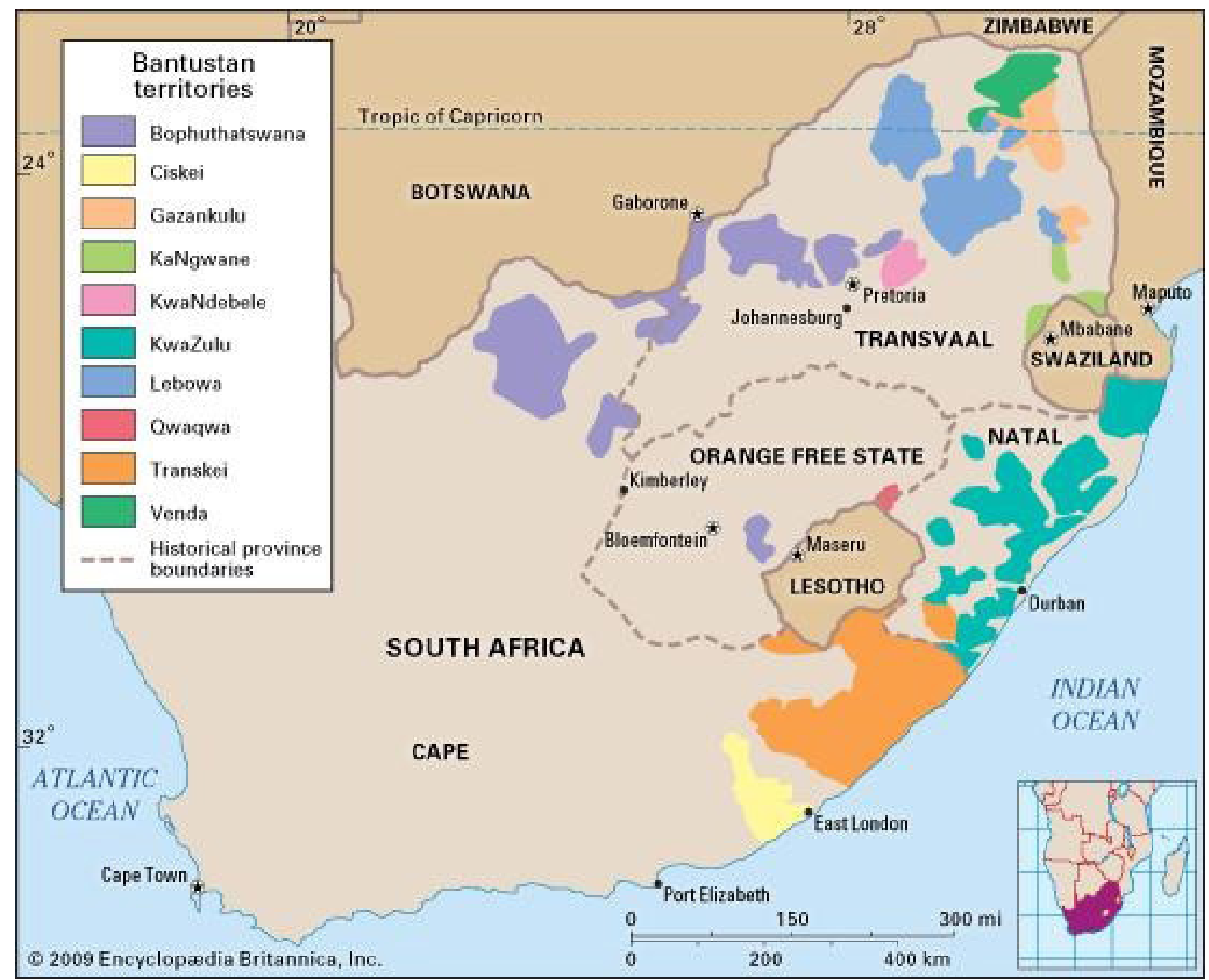

Já os Territórios Palestinos somam $6.220 \mathrm{~km}^{2}$, segundo as linhas do armistício de $1949^{27}$. Na Cisjordânia, porém, o mais amplo dos Territórios Palestinos, Israel exerce domínio total sobre $60 \%$ de seus $5.640 \mathrm{~km}^{2}$ - o que equivale à Área C, de administração

\footnotetext{
${ }^{24}$ Nelson Mandela Foundation. https://www.nelsonmandela.org/omalley/index.php/site/ q/03lv02424/04lv03370/05lv03389.htm

${ }^{25}$ Palestinian Central Bureau of Statistics - http://www.pcbs.gov.ps

${ }^{26}$ Encyclopaedia Britannica - http://www.britannica.com/topic/Bantustan

${ }^{27}$ Escritório das Nações Unidas para a Coordenação de Assuntos Humanitários.
} 
exclusivamente israelense $^{28}$. Excluída a Área $\mathrm{C}$, onde vivem cerca de 150 mil árabes $^{29}$, restam $2.256 \mathrm{~km}^{2}$ para mais de 4,5 milhões de palestinos - uma área 70 vezes menor do que a dos bantustões sul-africanos, que abriga o equivalente a aproximadamente a metade da população que os enclaves criados por Pretória abrigavam.

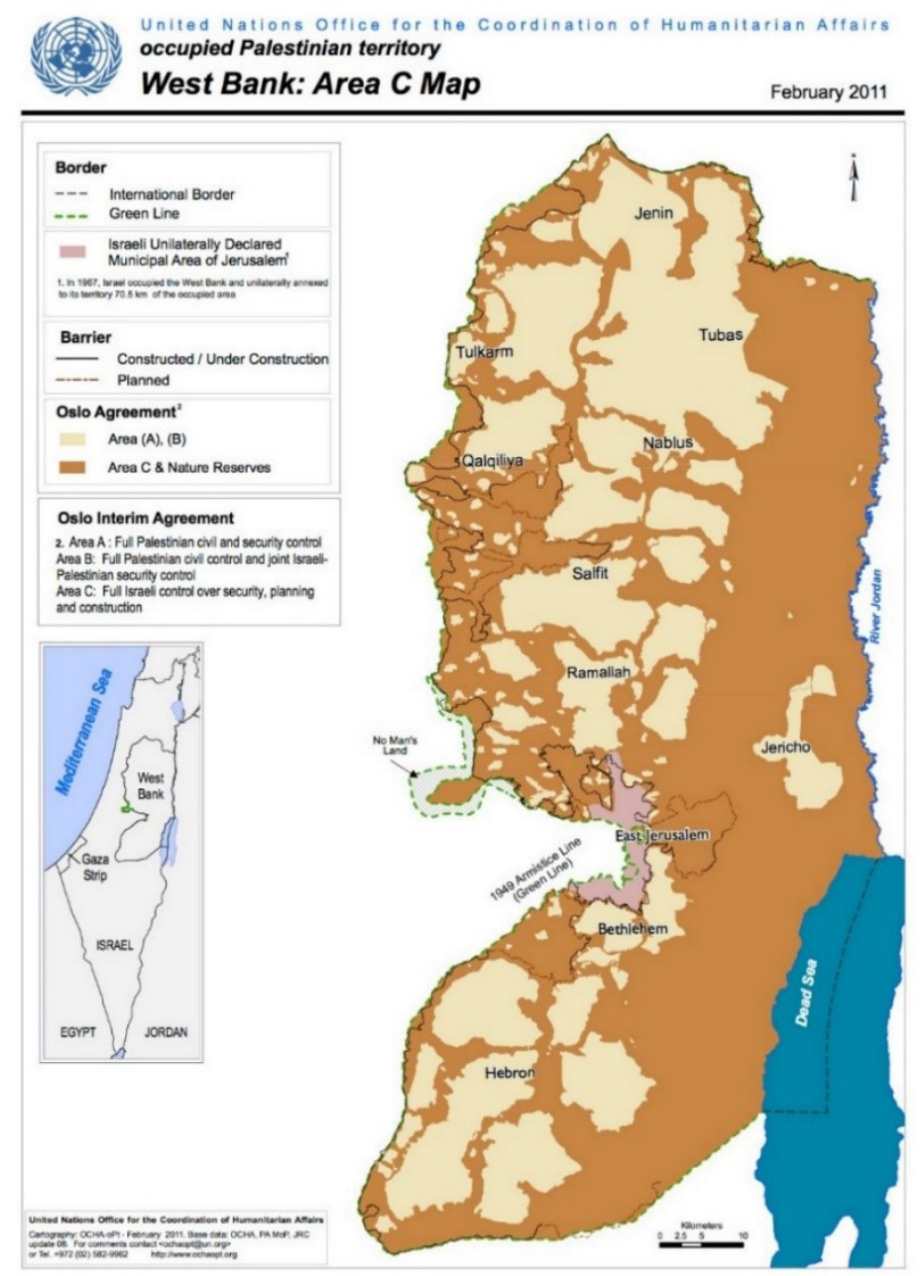

Conforme deixam claro os mapas, a quebra de contiguidade territorial ocorre tanto nos bantustões sul-africanos - apenas Ciskei e Venda tinham territórios contíguos como na Cisjordânia, com as cidades palestinas isoladas entre si pelas barreiras, estradas segregadas e assentamentos coloniais construídos por Israel.

Apesar de os níveis de autonomia variarem tanto nos bantustões sul-africanos, entre "independentes" e "autogovernados", quanto nos povoamentos palestinos, nas áreas $\mathrm{A}, \mathrm{B}$ ou $\mathrm{C}$, e denotarem, por este motivo, mais uma semelhança entre os Territórios Palestinos e as "homelands", há uma diferença fundamental nesse contexto:

Em repúdio ao apartheid e sua política de bantustões, que tinha o evidente objetivo de diminuir a um mínimo necessário a presença dos negros no território sul-africano e não da erradicação, já que a sociedade branca precisava do trabalho dos negros -, a comunidade internacional não reconheceu as "homelands" como estados ou semiestados.

\footnotetext{
${ }^{28}$ idem.
}

${ }^{29}$ idem. 
Críticos enfatizavam que os bantustões não representavam a totalidade das terras natais (o autorusa o termo "homelands") históricasafricanas e,mais especificamente, que economicamente e politicamente, eles eram inextricavelmente parte da África do Sul (...). A política de homeland causava aversão particularmente porque era usada para justificar a diminuição dos direitos de milhões de africanos que viviam nas cidades e zonas rurais (fora dos bantustões). ${ }^{30}$

O Estado da Palestina, por sua vez, tem amplo reconhecimento internacional, de 135 países $^{31}$. 0 reconhecimento do Estado da Palestina é uma causa popular. Em 30 de outubro de 2014, a Suécia se tornou o primeiro país da Europa Ocidental a reconhecer os Territórios Palestinos enquanto estado ${ }^{32}$. Em 26 junho de 2015, foi a vez do Vaticano, que reconheceu o Estado da Palestina após 15 anos de negociações ${ }^{33}$. Pelo menos 40 países e a União Europeia mantêm missões diplomáticas atualmente em Ramallah, que funciona como capital da Autoridade Nacional Palestina. 0 Estado da Palestina mantém pelo menos 33 missões estrangeiras, em todos os continentes.

Vale lembrar, ainda, que os bantustões da África do Sul foram estabelecidos em território nacional sul-africano, já a bantustização dos Territórios Palestinos ocorre em território estrangeiro ocupado.

\section{8 a 1966 - Bantustões e apartheid fora e dentro de Israel}

Leila Farsakh explica em seu estudo que "bantustização significa o processo pelo qual os Territórios Palestinos foram transformados em reservas populacionais de facto, dos quais os palestinos não podem sair sem possuir uma permissão das autoridades militares israelenses" ${ }^{34}$.

Esse processo iniciou-se na Primeira Guerra Árabe-Israelense (1948-1949), ocasionada, ao menos imediatamente, pela animosidade causada pela proposta de partição da Palestina entre árabes e judeus, aprovada pela ONU em 29 de novembro de 1947, e pelo ataque simultâneo de quatro países árabes - Egito, Jordânia, Síria e Iraque - em defesa dos palestinos, em 15 de maio de 1948, dia seguinte da declaração de independência de Israel. Os israelenses saíram-se vencedores do conflito, aumentando em $60 \%$ seu território em relação à proposta original de partição. "Em 7 de novembro de 1949, quando as armas finalmente silenciaram, 730.000 pessoas (árabes palestinos) tinham se tornado refugiados. ${ }^{35}$ ”

\footnotetext{
${ }^{30}$ BEINART, William. Twentieth Century South Africa, cap. 8, p. 218. Oxford: Oxford University Press, 2001.

${ }^{31}$ Autoridade Nacional Palestina - http://palestineun.org/about-palestine/diplomatic-relations/

${ }^{32}$ The Guardian - 30 out. 2014 - http://www.theguardian.com/world/2014/oct/30/sweden-officially-recognises-state-palestine

${ }^{33}$ The New York Times - 27 jun. 2015. http://www.nytimes.com/2015/06/27/world/middleeast/vatican -palestinian-state.html

${ }^{34}$ FARSAKH, Leila. What Future for Palestine: Independence or Bantustans. The Discourse of Sociological Practice, 7, 1/2, Spring/Fall 2005, p. 48.

${ }^{35}$ SHLAIM, Avi. Israel and Palestine: Reapprisals, Revisions, Refutations, cap. 4, p. 58. London/New York:
} 


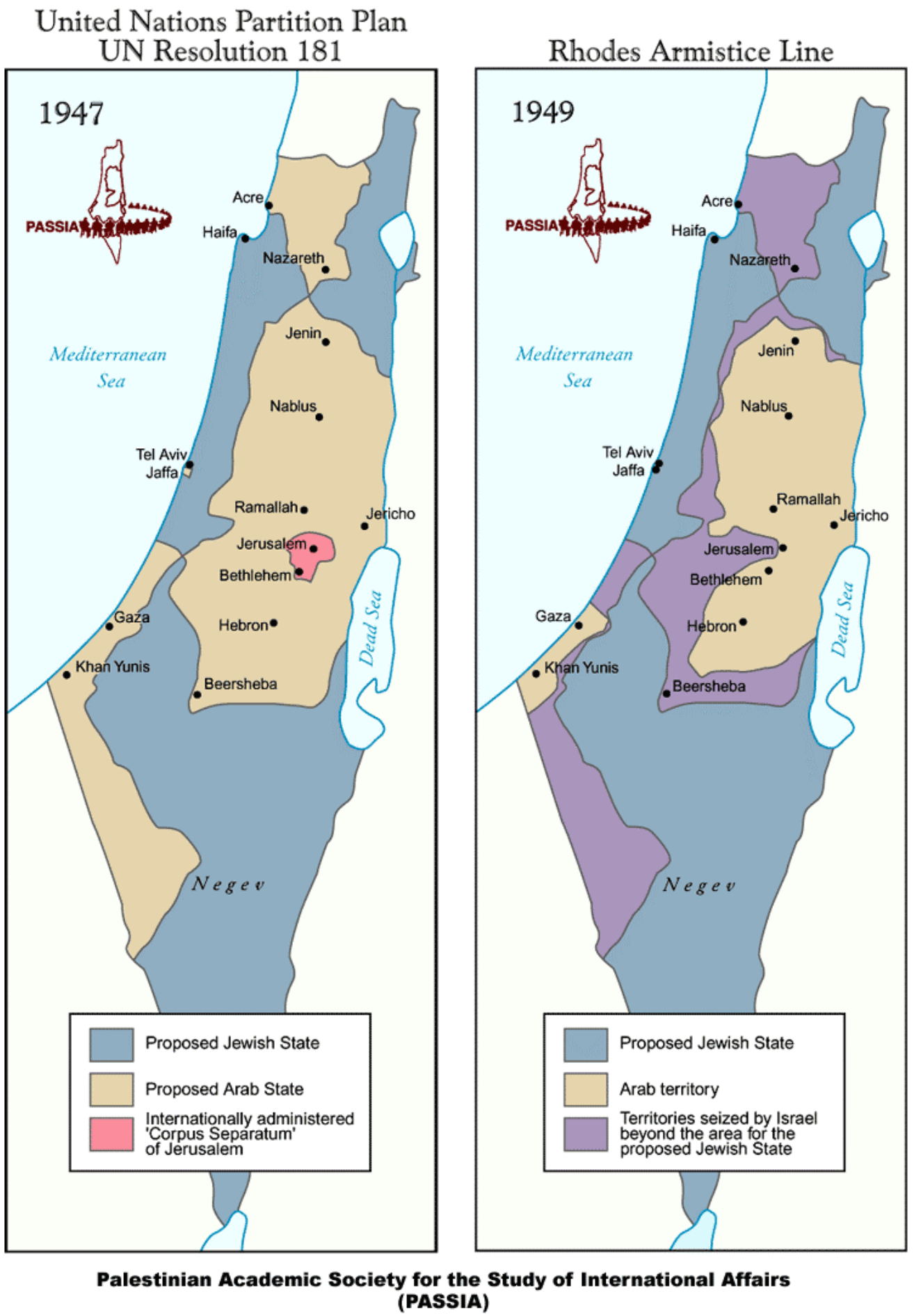

Historiadores israelenses revisionistas constataram na década de 1980 - após a abertura, por parte do governo israelense, dos arquivos da guerra de 1948 - que o conceito de "transferência” de população era fundamental no pensamento sionista. "'Transferência' é um eufemismo para a expulsão ou a remoção organizada da população nativa da Palestina para os países árabes vizinhos ${ }^{36 ”}$, explica Avi Shlaim, judeu de origem iraquiana, professor 
de relações internacionais da Universidade de Oxford, considerado um dos principais expoentes dos chamados "Novos Historiadores de Israel”, citando a conclusão de seu colega Nur Masalha. Nesse contexto, Shlaim cita ainda o historiador Benny Morris, que, em seu livro The Birth of the Palestinian Refugee Problem, 1947-1949 "dá numerosos exemplos específicos de guerra psicológica, de intimidação, de expulsão forçada e de atrocidades cometidas pelo jovem estado judeu"37.

Muitos dos palestinos expulsos de suas terras pelas forças israelenses se abrigaram em campos de refugiados na Cisjordânia e em Gaza, o que colaborou para a formação dos bantustões árabes nos territórios que seriam ocupados 20 anos depois. 0 deslocamento forçado dos refugiados palestinos é associável diretamente ao que ocorreu com os negros e as pessoas "de cor" - mestiços de origem africana e asiática - na África do Sul a partir dos anos 1950, após a oficialização das "homelands"38. "De 1960 a 1983, pelo menos 3,5 milhões de africanos foram removidos à força para os bantustões (...). Centenas de milhares também eram 'deportados' para os bantustões anualmente por violar as leis de circulação ${ }^{39 "}$, ressaltou o sociólogo Andy Clarno em seu estudo.

Apesar das diferentes cronologias, tanto Israel como África do Sul emergiram de projetos coloniais apoiados pelo Império Britânico. Uma característica proeminente desses projetos foi o uso da violência para deslocar africanos e palestinos, com o objetivo de produzir espaço para os colonos. Em ambos os casos, os estados/espaços foram constituídos por meio de guerras (1899-1902 na África do Sul; 1948 e 1967 em Palestina/Israel). ${ }^{40}$

Após a guerra de 1948, porém, os cerca de 200 mil árabes que permaneceram em Israel - que nunca chegaram a representar mais do que $20 \%$ da população do país ${ }^{41}$ - também foram objeto de uma política de bantustização análoga à do apartheid sul-africano, segundo a análise de Leila Farsakh:

Historicamente, a política israelense em relação aos palestinos que permaneceram sob seu controle entre 1948 e 1966 tinha muitos elementos de um sistema de apartheid. Os que passaram a ser chamados de palestinosisraelenses (ou árabes-israelenses, no jargão atual) foram despojados de suas terras e seus vilarejos, tiveram restringidos lugares de trabalho e residência e não podiam se movimentar sem um passe emitido pela autoridade militar. Não lhes foi concedida autonomia de nenhuma maneira e, em 1966, as restrições à sua mobilidade foram removidas. A questão sobre sua representação política foi 'resolvida' pela inclusão deles na política israelense, precisamente após eles terem sido transformados em uma minoria dentro de sua própria terra. ${ }^{42}$

\footnotetext{
${ }^{37}$ idem.

${ }^{38} \mathrm{O}$ historiador sul-africano William Beinart afirma que 600 mil pessoas "de cor" sofreram deslocamentos forçados em razão do Group Areas Act, de 1950, em três décadas de vigência da lei.(BEINART, 2001: p. 153).

${ }^{39}$ CLARNO, Andy. The Constitution of State/Space and the Limits of 'Autonomy' in South Africa and Palestine/Israel. Conference Papers, American Sociological Association, 16 jan. 2008, p. 10.

${ }^{40}$ CLARNO, Andy. The Constitution of State/Space and the Limits of 'Autonomy' in South Africa and Palestine/Israel. Conference Papers, American Sociological Association, 16 jan. 2008, p. 3.

${ }^{41}$ Israeli Central Bureau of Statistics.

${ }^{42}$ FARSAKH, Leila. What Future for Palestine: Independence or Bantustans. The Discourse of Sociological
} 


\title{
1967 A 1993 - DIVIDIR PARA GOVERNAR: ANEXAÇÃO VELADA E FRAGMENTAÇÃo EFETIVA DOS TERRITÓRIOS PALESTINOS
}

A fragmentação da contiguidade territorial dos Territórios Palestinos, operada inicialmente pela construção de assentamentos coloniais israelenses na Cisjordânia, na Faixa de Gaza e em Jerusalém Oriental, a partir da década de 1970, foi posta em prática após a ocupação militar de 1967, fruto da Guerra dos Seis Dias.

\begin{abstract}
Entre 1970 e 1993, Israel construiu mais de 145 assentamentos e instalou (nos Territórios Palestinos) 196 mil colonos, metade deles vivendo em 11 assentamentos em torno de Jerusalém Oriental. 0 crescimento exponencial dos assentamentos ocorrido com a chegada do Likud ao poder em 1997 lançou as bases da fragmentação territorial da Cisjordânia e da Faixa de Gaza. ${ }^{43}$
\end{abstract}

Leila Farsakh ressaltou que, o governo israelense expropriou e cercou aproximadamente de $36 \%$ a $39 \%$ das terras na Cisjordânia e em Gaza ${ }^{44}$ e permitiu a transferência de colonos israelenses aos territórios ocupados, apesar da ilegalidade de tal transferência, de acordo com a $4^{\text {a }}$ Convenção de Genebra ${ }^{45}$. Afirmando que seus assentamentos "não têm a intenção de deslocar habitantes árabes e nem o fazem na prática", o governo israelense não os considera ilegais sob a $4{ }^{\mathrm{a}}$ Convenção de Genebra ${ }^{46}$. "Por outro lado, o governo militar (israelense) na Cisjordânia e na Faixa de Gaza estabeleceu diferentes conjuntos de leis militares e decretos que regularam a vida civil, econômica e legal dos habitantes palestinos ${ }^{47}$."

\section{DE 1993 EM DIANTE - INSTITUCIONALIZAÇÃO DOS BANTUSTÕES PALESTINOS: OSLO, FRUSTRAÇõES E A AUSÊNCIA DE LUZ NO FIM DO TÚNEL}

"Ao institucionalizar os processos contraditórios de separação social e integração territorial que Israel criou entre 1967 e 1993, o processo de Oslo consolidou o caminho para a 'bantustização' da Cisjordânia e da Faixa de Gaza ${ }^{48 ", ~ c o n s t a t o u ~ L e i l a ~ F a r s a k h . ~ A ~}$ cientista política enumerou em seu estudo três elementos principais da estrutura legal dos Acordos de Oslo que colocam "a entidade palestina em uma posição similar à dos bantustões sul-africanos sob o regime do apartheid"49.

\footnotetext{
Practice, 7, 1/2, Spring/Fall 2005, p. 52.

${ }^{43}$ FARSAKH, Leila. What Future for Palestine: Independence or Bantustans. The Discourse of Sociological Practice, 7, 1/2, Spring/Fall 2005, p. 51.

${ }^{44}$ FARSAKH, Leila. Palestinian Labour Migration to Israel, p. 110. London: Routledge, 2005.

${ }^{45}$ FARSAKH, Leila. What Future for Palestine: Independence or Bantustans. The Discourse of Sociological Practice, 7, 1/2, Spring/Fall 2005, p. 51.

${ }^{46}$ Israel Ministry of Foreign Affairs - Israeli Settlements and International Law. www.israel-mfa.gov.il

${ }^{47}$ FARSAKH, Leila, op. cit., p. 52.

48 ibidem, p. 54.

${ }^{49}$ idem.
} 
Primeiramente, Oslo falhou ao não garantir o fim da ocupação de Israel e sua retirada da Cisjordânia e da Faixa de Gaza. Como nos bantustões sul-africanos, Oslo não tornou o eleitorado nativo a única fonte de autoridade para a entidade palestina ${ }^{50}$.

De fato, em 5 outubro de 1995, o então premiê israelense, Yitzhak Rabin, deixou claro à Knesset que acabar com a ocupação dos Territórios Palestinos nunca foi sua intenção.

Aolongo de seu discurso, Rabin expôs sua ideia para o assentamento permanente:
presença militar, mas não a anexação, do Vale do Jordão; retenção de grandes
blocos de assentamentos próximos à fronteira de 1967; preservação de uma
Jerusalém unida, com respeito pelos direitos das outras religiões; e uma entidade
palestina que seria menos que um estado e cujo território seria desmilitarizado. ${ }^{51}$

Uma semana antes, Rabin tinha assinado em Washington - juntamente com o líder da Organização para a Libertação da Palestina, Yasser Arafat, na presença dos presidentes americano, Bill Clinton, e egípcio, Hosni Mubarak, além do rei Hussein, da Jordânia - o Acordo Provisório Israelense-Palestino sobre a Cisjordânia e a Faixa de Gaza, que ficou conhecido como Oslo 2 e ratificou a organização de "eleições para um Conselho Palestino, a transferência de autoridade legislativa para este conselho, a retirada das forças israelenses dos centros populacionais palestinos e a divisão dos territórios em três áreas - A, B e C"52. 0 assassinato de Rabin, em 4 de novembro de 1995, e o retorno do Likud ao poder - sob a batuta de Binyamin Netanyahu - nas eleições que se seguiram, no fim de maio de 1996, são apontados por Avi Shlaim como as principais causas do fracasso dos Acordos de Oslo.

Após ressaltar que a Autoridade Nacional Palestina "continuou dependente da autoridade militar israelense na Cisjordânia e na Faixa de Gaza, juntamente com a Administração Civil Israelense, que não foram desmanteladas ${ }^{53 "}$ pelo pacto provisório e que os palestinos não obtiveram "jurisdição territorial plena, nem lhes foi concedida nenhuma identidade soberana", Leila Farsakh constata a segunda similaridade entre a estrutura legal que rege os Territórios Palestinos e a dos bantustões sul-africanos: "Oslo não afirmou a superioridade do direito internacional sobre a lei israelense, que tem governado os Territórios Palestinos ocupados desde $1967^{54 "}$.

Essa situação persiste até hoje. Em reportagem publicada em 14 de setembro de 2015 sobre uma nova cidade construída nas imediações de Ramallah, denominada Rawabi, o primeiro empreendimento do tipo feito no Estado da Palestina, que acabava de ficar pronto, o jornal espanhol El País deixa clara essa relação de dependência.

\footnotetext{
50 idem.

${ }^{51}$ SHLAIM, Avi. Israel and Palestine: Reapprisals, Revisions, Refutations, cap. 16, p. 202. London/New York: Verso, 2010.

52 ibidem, p. 201-202.

${ }^{53}$ FARSAKH, Leila. What Future for Palestine: Independence or Bantustans. The Discourse of Sociological Practice, 7, 1/2, Spring/Fall 2005, p. 54.

${ }^{54}$ FARSAKH, Leila. What Future for Palestine: Independence or Bantustans. The Discourse of Sociological Practice, 7, 1/2, Spring/Fall 2005, p. 54.
} 
Uma estreita estrada se entronca com a via expressa de número 60, que percorre um rosário de assentamentos de colonos judeus, conduz até esse projeto urbanístico de 1,075 bilhão de euros. Seu custo disparou, em razão de atrasos na concessão do abastecimento de água e a abertura dos acessos, que dependem, em grande medida, da chamada Administração Civil do Exército israelense, órgão que administra $60 \%$ do território da Cisjordânia. ${ }^{55}$

A localidade já começava a ser povoada por palestinos capazes de comprar à vista ou financiar apartamentos e tem capacidade para abrigar 40 mil habitantes.

\begin{abstract}
Em terceiro lugar, os pactos de Oslo tiveram como foco o estabelecimento de uma infraestrutura de cooperação próxima entre as partes israelense e palestina para a transferência de responsabilidades civis e de segurança, como foi o caso com a transferência de autoridade do governo branco da África do Sul para os bantustões. (...) Um dos primeiros elementos que Oslo 1 e o Acordo Provisório solicitavam era o estabelecimento de uma força policial palestina para garantir a ordem pública que cooperaria proximamente com o lado israelense em temas de segurança. Contudo, Israel continuou a ter superioridade nas questões de segurança. Esse tipo de cooperação de segurança também era solicitado nos bantustões da África do Sul. ${ }^{56}$
\end{abstract}

Na tentativa seguinte de negociações, em Camp David, em 2000, Israel prometeu se retirar da Faixa de Gaza e apresentou uma proposta de partição da Cisjordânia que, em razão da anexação de território que o governo israelense pretendia oficializar, onde se localizam assentamentos coloniais, criaria três bolsões palestinos não contíguos e isolaria Jericó e outras localidades menores, segundo o mapa proposto por Israel. 0 Vale do Jordão ficaria "temporariamente" sob controle israelense e passaria para controle palestino, eventualmente.

"A cúpula de Camp David em julho de 2000 não garantiu um fim ao processo de bantustização. ${ }^{57 "}$ Não houve acordo e, se houvesse, pelo menos cinco bantustões palestinos - o norte, o centro e o sul da Cisjordânia, mais Jericó e Gaza - seriam oficializados permanentemente nos territórios cravejados de assentamentos coloniais israelenses. $\mathrm{E}$ mesmo que Israel devolvesse o Vale do Jordão aos palestinos, a contiguidade territorial palestina continuaria interrompida.

\title{
A CONCRETIZAÇÃO DA POLÍTICA ISRAELENSE DE BANTUSTIZAÇÃO DA PALESTINA: O "MURO DO APARTHEID”
}

Em 16 de junho de 2002, em meio à violência da Segunda Intifada, "Israel inicia a construção de sua barreira de segurança na Cisjordânia, uma estrutura de 640 quilômetros de extensão projetada para manter homens-bomba palestinos fora de Israel $^{58 ”}$. O levante

\footnotetext{
${ }^{55}$ El País - 14 set. 2015. http://internacional.elpais.com/internacional/2015/09/14/actualidad/1442256863_699144.html?id_externo_rsoc=FB_CM

${ }^{56}$ FARSAKH, Leila, op. cit., p. 55.

${ }^{57}$ FARSAKH, Leila. What Future for Palestine: Independence or Bantustans. The Discourse of Sociological Practice, 7, 1/2, Spring/Fall 2005, p. 55.

${ }^{58}$ BBC News - Al-Aqsa Intifada Timeline - http://news.bbc.co.uk/2/hi/middle_east/3677206.stm
} 


\section{West Bank Final Status Map}

Presented by Israel - May 2000

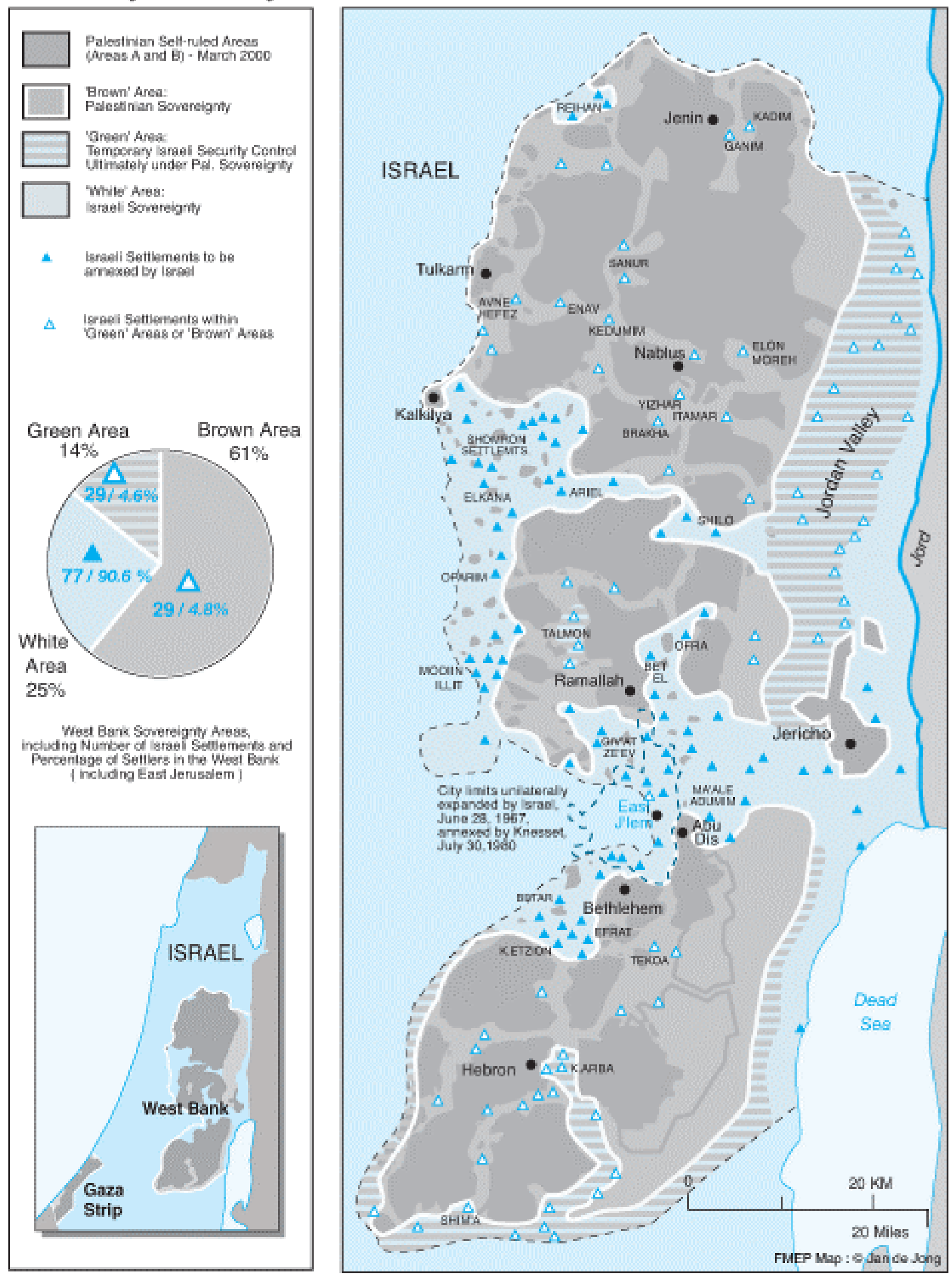


palestino contra a ocupação israelense tinha sido desencadeado em 28 de setembro de 2000, quando uma visita de Ariel Sharon, líder do Likud na época e eleito premiê no ano seguinte, ao complexo de Al-Haram Al-Sharif, na Cidade Antiga de Jerusalém Oriental, provocou uma reação violenta da população palestina, que evoluiu para um conflito aberto que durou até fevereiro de $2005^{59}$.

Transformada em uma barreira de concreto chamada de Muro do Apartheid pelos críticos das políticas israelenses em relação aos palestinos, a estrutura de separação tem estimados 85\% de sua construção realizada dentro dos Territórios Palestinos e isola entre si cidades e vilarejos palestinos. 0 muro separa ainda Jerusalém Oriental da Cisjordânia.

Em julho de 2004, a Corte Internacional de Justiça condenou a construção da barreira.

0 tribunal considera que a construção do muro e o regime de trânsito a este associado criam um 'fait accompli' concreto que poderia facilmente se tornar permanente, situação que - independentemente da caracterização formal por parte de Israel - seria equivalente a uma anexação de facto. Aquela construção e outras medidas tomadas anteriormente impediram, desta maneira, o exercício do direito de autodeterminação do povo palestino. ${ }^{60}$

A posição do tribunal reflete o pensamento mais comum na comunidade internacional. Até o governo americano de George W. Bush manifestou contrariedade quanto à construção da barreira. "Uma nação tem o direito de erguer uma cerca se vir necessidade para isso. No caso da cerca israelense, a preocupação é ela invadir a terra dos outros $^{61}$ ", afirmou, em 5 de agosto de 2003, o então secretário de estado norte-americano, Colin Powell, durante uma transmissão a países árabes.

A construção do muro, porém, continuou. E os bantustões palestinos foram cercados por toneladas de concreto também na Cisjordânia, a exemplo do que já havia ocorrido na Faixa de Gaza.

Por meio de remoções forçadas, demolições de lares, confiscos de terras, construções de muros, escavações de trincheiras e outras incontáveis operações militares, África do Sul e Israel concentraram à força as populações colonizadas dentro de espaços estritamente delimitados. Apesar da retórica de 'autonomia' e 'independência', os sul-africanos negros nunca exerceram soberania nos bantustões, como não o fazem os palestinos em seus enclaves. Em vez disso, a produção desses espaços 'autônomos' formou parte de estratégias para garantir uma operação contínua de soberania colonial sobre todo o território da África do Sul e de Palestina/Israel ${ }^{62}$.

\footnotetext{
${ }^{59}$ O Nobre Santuário, que abriga o Domo da Rocha e a Mesquita de Al-Aqsa, é considerado o terceiro local mais sagrado do islamismo. A parede oeste do Monte do Templo, como os judeus denominam o complexo, é o chamado Muro das Lamentações, o lugar mais sagrado do judaísmo.

${ }^{60}$ The Guardian - 09 jul. 2004. http://www.theguardian.com/world/2004/jul/09/israelandthepalestinians.unitednations

${ }^{61}$ Associated Press - 05/08/2003.

${ }^{62}$ CLARNO, Andy. The Constitution of State/Space and the Limits of 'Autonomy' in South Africa and Pales-
} 
artigo

\section{DEPENDÊNCIA E POBREZA: A ECONOMIA E OS BANTUSTÕES PALESTINOS E SUL- AFRICANOS}

Enquanto as origens dos bantustões sul-africanos remontam a uma clara intenção do governo sul-africano de suprir uma demanda por força de trabalho barata ${ }^{63}$, a bantustização dos Territórios Palestinos obedeceu a uma lógica reversa, que excluiu a população palestina do mercado de trabalho israelense, em razão "da reestruturação neoliberal $^{64 "}$ da economia de Israel "que acompanhou Oslo ${ }^{65 "}$ ", constatou Andy Clarno.

A descoberta de ouro e diamantes na África do Sul do fim do século 19 gerou uma demanda imediata por grande oferta de trabalho barato e não qualificado. Repentinamente dependentes de trabalhadores africanos, os colonos europeus não podiam continuar a simplesmente deslocar os nativos, expulsando-os do território. Em vez disso, eles estabeleceram reservas territoriais separadas posteriormente conhecidas como bantustões - como uma estratégia espacial para regular a força de trabalho africana, governar a população africana e manter uma separação física entre os colonizadores e os colonizados. ${ }^{66}$

Citando o livro The Crisis in South Africa, de John Saul e Stephen Gelb ${ }^{67}$, Andy Clarno, analisou que:

A ideologia do 'apartheid' (sul-africano) depois de 1948 contribuiu para o crescimento de uma economia fordista centralizada e racial baseada em apoio governamental para a produção doméstica, a divisão no mercado de trabalho e em um sistema de previdência social para trabalhadores brancos baseado na superexploração de trabalhadores negros. Como parte deste sistema, as 'reservas nativas' existentes foram reorganizadas em 'bantustões' definidos etnicamente e autogovernados. ${ }^{68}$

Desta maneira, a economia dos bantustões sul-africanos era totalmente dependente do regime do apartheid.

A dependência econômica dos Territórios Palestinos é outro fator importante de comparação com o sistema sul-africano. "Anteriormente à irrupção da Segunda Intifada, em 2000, 22\% dos palestinos com emprego trabalhavam em Israel ou em assentamentos israelenses ${ }^{69 \prime}$, ressaltava The Washington Institute for Near East Policy, em sua análise política de 23 de março de 2006.

tine/Israel. Conference Papers. American Sociological Association, 16 jan. 2008, p. 4.

${ }^{63}$ LESTER, Alan. From colonization to democracy: A new historical geography of South Africa. London: I.B. Tauris Publishers, 1998.

${ }^{64}$ CLARNO, Andy. The Constitution of State/Space and the Limits of 'Autonomy' in South Africa and Palestine/Israel. Conference Papers, American Sociological Association, 16 jan. 2008, p. 5.

${ }^{65}$ idem.

${ }^{66}$ ibidem, p. 10.

${ }^{67}$ SAUL, John; GELB, Stephen. The Crisis in South Africa. New York: Monthly Review Press, 1986.

${ }^{68}$ CLARNO, Andy, op. cit., p. 8.

${ }^{69}$ The Washington Institute for Near East Policy, Policywatch \#1088. Palestinian Economic Dependence on Israel, 23 mar. 2006.

http://www.washingtoninstitute.org/policy-analysis/view/palestinian-economic-dependence-on-israel 
De acordo com o Banco Mundial, em 2000, a economia palestina era uma das economias mais dependentes de remessas no mundo, com a renda gerada fora dos territórios compreendendo 21\% do Produto Nacional Bruto (PNB). Enquanto o Banco Mundial notou que é importante que os palestinos se "afastem de uma dependência em exportação de trabalho para Israel e se aproximem de um caminho de crescimento baseado na exportação de produtos e serviços para Israel e outros países", ele também reconheceu que, no período intermediário, "uma prioridade deve ser dada a preservar o emprego".70

A análise de The Washington Institute for Near East Policy lembrava que "Israel anunciou planos para diminuir o número total de trabalhadores estrangeiros e eliminar gradualmente as permissões de trabalho para palestinos até o fim de 2007"71.

Leila Farsakh ressaltou em seu estudo que, "entre 1967 e 1990, as fronteiras entre Israel e os Territórios Ocupados eram mantidas abertas".

Trabalhadores palestinos empregados em Israel representavam mais de um terço da força de trabalho palestina e geravam mais de um quarto do PIB dos territórios. Israel também era o mercado para 90\% das importações palestinas e 70\% de suas exportações, entre 1975 e 1990. Depois de 1990, Israel começou a restringir movimentos laborais e populacionais, introduzindo as políticas de restrição à circulação e concessão de autorizações sem dar aos palestinos a possibilidade para a independência econômica. ${ }^{72}$

Para Andy Clarno, porém, Leila Farsakh "não levou em conta a reestruturação neoliberal que acompanhou o processo de Oslo e contribuiu para a exclusão dos trabalhadores palestinos ${ }^{73 "}$ :

Como parte da tentativa do estado (sul-africano) de regular uma economia fordista racial, os bantustões foram constituídos para assegurar acesso contínuo a mão de obra africana barata para as minas. (...) As restrições à circulação israelenses, por outro lado, vieram acompanhados da eliminação dos trabalhadores palestinos da economia israelense. Uma história comum por todo o mundo, a neoliberalização em Palestina/Israel produziu um 'excedente' de população 'descartável': permanentemente desempregada, pobre demais para consumir, separada dos meios de subsistência e abandonada pelo estado neoliberal. ${ }^{74}$

Em Palestina/Israel, a reestruturação neoliberal contribuiu para constituir uma nova estratégia israelense de controle indireto por meio de políticas de separação e confinamento. ${ }^{75}$

A dependência de Israel da economia palestina também se evidencia pelo repasse mensal de US\$ 127 milhões que o governo israelense recolhe em impostos para a Autoridade Nacional Palestina, cobrados sobre as mercadorias que passam por Israel para serem comercializadas nos Territórios Palestinos.

\footnotetext{
70 idem.

${ }^{71}$ idem.

${ }^{72}$ FARSAKH, Leila. What Future for Palestine: Independence or Bantustans. The Discourse of Sociological Practice, 7, 1/2, Spring/Fall 2005, p. 52.

${ }^{73}$ CLARNO, Andy. The Constitution of State/Space and the Limits of 'Autonomy' in South Africa and Palestine/Israel. Conference Papers, American Sociological Association, 16 jan. 2008, p. 5.

${ }^{74}$ ibidem, p. 17.

75 ibidem, p. 1.
} 
Em 2011, segundo o Banco Mundial, 25,8\% da população da Cisjordânia e de Gaza era pobre $^{76}$. 0 índice de desemprego nos Territórios Palestinos, no fim do primeiro semestre de 2015, era de 24,8\%. Assim como a dependência da potência dominadora, a pobreza também é uma característica similar entre os bantustões sul-africanos ${ }^{77}$ e os palestinos.

\section{AS RELAÇõES ENTRE ISRAEL E A ÁFRICA DO SUL DO APARTHEID: PROFUNDAS E COMPROMETEDORAS}

Em desafio às críticas e aos embargos da comunidade internacional em relação ao apartheid sul-africano, o governo israelense manteve entre a década de 1970 e 1994, quando a recém-instituída democracia na África do Sul elegeu Nelson Mandela presidente, relações intensas com Pretória e suas "homelands". A cooperação entre os países se deu principalmente nas áreas militar, atômica e comercial, segundo comprovam diversos estudos. Dadas, porém, suas amplas e particulares dimensões, as complexidades e contradições intrínsecas, além dos segredos envolvidos, a análise dessas relações seria uma outra - e árdua - tarefa, como demonstra o livro The Unspoken Alliance: Israel's Secret Relationship with Apartheid South Africa, do historiador Sasha Polakow-Suransky, editor de Opinião Internacional do jornal norte-americano The New York Times, doutor pela Universidade Oxford. Mas, já que este artigo compara e discute similaridades e diferenças entre bantustões sul-africanos e palestinos, vale notar que sim, o governo de Israel, um país formado por um povo vítima de um racismo genocida, manteve profundas relações com o racista regime do apartheid da África do Sul.

O marco do início da cooperação foi a visita a Israel do premiê sul-africano Balthazar Johannes Vorster, em abril de 1976, a convite de seu homólogo israelense, Yitzhak Rabin.

Além de ser o arquiteto da brutal repressão sul-africana contra a oposição democrática dos negros (...), Vorster e seu chefe de inteligência, Hendrik van den Bergh, serviram como generais na Ossewa Brandwag, uma organização militante africâner que apoiou abertamente os nazistas durante a $2^{\mathrm{a}}$ Guerra Mundial. ${ }^{78}$

Na viagem, Vorster visitou o Yad Vashem, o museu em memória às vítimas do Holocausto erguido em Jerusalém.

A pesquisadora Jane Hunter - editora da publicação Israeli Foreign Affairs entre 1985 e 1993 - constatou que "o desenvolvimento de armas nucleares" foi um dos principais frutos da colaboração iniciada com a visita do líder do apartheid a Israel.

Um importante componente dos acordos de 1976 com Vorster foi a 'troca' de expertise (atômico) israelense pelo urânio sul-africano e seu amplo espaço

\footnotetext{
${ }^{76}$ Banco Mundial - http://data.worldbank.org/country/west-bank-gaza

${ }^{77}$ Encyclopaedia Britannica - http://www.britannica.com/topic/Bantustan

${ }^{78}$ POLAKOW-SURANSKY, Sasha. The Unspoken Alliance: Israel's Secret Relationship with Apartheid South Africa. New York: Vintage Books, 2010.
} 
terrestre e marítimo para testes de armas nucleares. 0 teste ocorreu em setembro de 1979, no Atlântico Sul, em um momento em que Israel tinha um potencial nuclear mais altamente desenvolvido que sua parceira, a África do Sul. ${ }^{79}$

Estima-se que, atualmente, Israel possua pelo menos 80 ogivas nucleares ${ }^{80}$. 0 governo sul-africano, por outro lado, chegou a construir seis armas atômicas na década de 1980, mas anunciou em 1993 o fim de seu programa militar nuclear, admitindo que tentou obter armamento nuclear entre 1974 e $1990^{81}$.

Após os acordos de Vorster, o fluxo de intercâmbio militar entre Israel e África do Sul assumiu uma forma simbiótica: tecnologia e armas acabadas de Israel eram trocadas por matérias-primas e dinheiro da África do Sul, um padrão também encontrado em suas relações econômicas ${ }^{82}$

Além de vender tecnologia nuclear e os armamentos comuns, usados pelo apartheid sul-africano na repressão aos negros, o que já desafiava o embargo internacional que pressionava Pretória, Israel ajudou a África do Sul a burlar boicotes e exportar seus produtos para Europa e Estados Unidos.

As matérias-primas ou mercadorias semiacabadas sul-africanas (produzidas por negros sul-africanos) são enviadas para Israel, onde são mais manufaturadas ou montadas até que o valor mínimo legal seja adicionado; então, com um selo 'Made in Israel', esses bens são exportados. ${ }^{83}$

Jane Hunter informava ainda que Israel contrariava as determinações da comunidade internacional encontrando-se com autoridades dos bantustões sul-africanos, mantendo comércio e cooperação agrícola com as "homelands", fornecendo segurança aos líderes das reservas e investindo, por meio de seus empresários, nos territórios segregados por Pretória ${ }^{84}$. Em agosto de 1985, o ministro-chefe do bantustão de Kwazulu, Gatsha Buthelezi, fez uma visita a Israel, em busca de apoio "educacional, agrícola e tecnológico" do governo israelense $\mathrm{e}^{85}$.

\section{CONCLUSÃO}

Quando estive em Israel e na Cisjordânia, em setembro de 2011, passei a me questionar sobre se há realmente argumentos que corroboram as críticas que qualificam as políticas do governo israelense em relação aos palestinos como políticas racistas, de apartheid, ou se essas comparações eram meramente fruto de raiva - pois, além de comuns, ${ }^{79}$ HUNTER, Jane. Israel and the Bantustans. Journal of Palestinian Studies, v. 15, n. 3, 1986, p. 56.

${ }^{80}$ Nuclear Threat Initiative - http://www.nti.org/gsn/article/israel-estimated-possess-80-nuclear-weapons-report/

${ }^{81}$ Nuclear Threat Initiative - http://www.nti.org/country-profiles/south-africa/nuclear/

${ }^{82}$ HUNTER, Jane, op. cit., p. 55.

${ }^{83}$ HUNTER, Jane. Israel and the Bantustans. Journal of Palestinian Studies, v. 15, n. 3, 1986, p. 58.

${ }^{84}$ ibidem, p. 60.

${ }^{85}$ ibidem, p. 70. 
tais afirmações configuram lugares-comuns. O negociador palestino Xavier Abu Eid, um dos entrevistados pelo grupo de jornalistas brasileiros que eu compunha no início dessa viagem - patrocinada, aliás, pelo American Jewish Comitee -, expôs à comitiva, em um fino restaurante de Ramallah, uma teoria peculiar para evidenciar o "apartheid israelense": dissolver a Autoridade Nacional Palestina, para que a anexação dos Territórios Ocupados se concretize numa solução de um estado e para que o tratamento concedido por Israel aos "árabes-israelenses" oriundos da Cisjordânia e da Faixa de Gaza evidencie sua condição de cidadãos de segunda classe. Segundo essa visão, o "apartheid judaico" não estaria ainda configurado totalmente, já que os palestinos da Cisjordânia e da Faixa de Gaza recebem o tratamento de um povo estrangeiro sob ocupação ${ }^{86}$.

Pesquisar as comparações para o presente artigo colocou-me em contato com argumentos concretos que corroboram as opiniões de quem qualifica a política israelense em relação aos palestinos e aos Territórios Ocupados como uma política de apartheid. Há quatro anos, os campos de refugiados que conheci na Cisjordânia me pareceram favelas semiurbanizadas, como pareceriam ou podem parecer para qualquer latino-americano desavisado - exceto pelo "detalhe" de que os povoamentos palestinos formam bolsões isolados entre si pelos muros israelenses e pelas estradas segregadas, que conectam assentamentos coloniais israelenses a Israel e aos demais territórios que o país ocupa.

De acordo com o negociador palestino, quando esteve na região, em 2009, o arcebispo sul-africano Desmond Tutu ficou impressionado com as estradas da Cisjordânia, que restringem o acesso dos palestinos, não chegam a cidades e vilarejos árabes da região e, ainda por cima, são cercadas por muralhas e arame farpado. "Ele lembrou que nem nos piores anos do apartheid segregaram as estradas". 87

Portanto, concluo que não há nenhum tipo de exagero - ou muito menos antissemitismo, conforme costumam ser acusados os críticos de Israel e suas políticas em qualificar o governo israelense como um regime análogo ao do apartheid sul-africano.

\footnotetext{
${ }^{86}$ O Estado de S.Paulo - 18 set. 2011 - http://internacional.estadao.com.br/noticias/geral,se-adesao-fracassar-autoridade-palestina-pode-ser-desfeita-imp-,773969

87 O Estado de S.Paulo - 18 set. 2011 - http://internacional.estadao.com.br/noticias/geral,se-adesao-fracassar-autoridade-palestina-pode-ser-desfeita-imp-,773969
} 
artigo

\section{Fontes Bibliográficas}

\section{Livros}

BEINART, William. Twentieth Century South Africa. Oxford: Oxford University Press, 2001.

BLOCH, Marc. Mélanges historiques: Pour une histoire comparée des sociétés européennes. Paris: CNRS Editions, 1963.

FARSAKH, Leila. Palestinian Labour Migration to Israel. London: Routledge, 2005.

HAUPT, Heinz-Gerhard. O Lento Surgimento de uma História Comparada. Passados recompostos; campos e canteiros da história. Rio de Janeiro: Editora FGV, 1998.

LESTER, Alan. From colonization to democracy: A new historical geography of South Africa. London: I.B. Tauris Publishers, 1998.

MORRIS, Benny. The Birth of the Palestinian Refugee Problem, 1947-1949. Cambridge: Cambridge Middle East Library, 1989.

POLAKOW-SURANSKY, Sasha. The Unspoken Alliance: Israel's Secret Relationship with Apartheid South Africa. New York: Vintage Books, 2010.

SAUL, John; GELB, Stephen. The Crisis in South Africa. New York: Monthly Review Press, 1986.

SHLAIM, Avi. Israel and Palestine: Reapprisals, Revisions, Refutations. London/New York: Verso, 2010.

\section{Periódicos acadêmicos}

CLARNO, Andy. The Constitution of State/Space and the Limits of 'Autonomy' in South Africa and Palestine/Israel. Conference Papers, American Sociological Association, 2008.

FARSAKH, Leila. What Future for Palestine: Independence or Bantustans. The Discourse of Sociological Practice, 7, 1/2, 2005.

HUNTER, Jane. Israel and the Bantustans. Journal of Palestinian Studies, v. 15, n. 3, 1986.

PRADO, Maria Lígia Coelho. América Latina: Historia Comparada, Historias Conectadas, Historia Transnacional. Anuario Digital $n^{\circ}$ 24, Escuela de Historia, Universidad Nacional de Rosario, 2012.

\section{Veículos de imprensa}

Associated Press

BBC News

El País

Middle East Monitor 
artigo

O Estado de S.Paulo

The Guardian

The New York Times

\section{Bases de dados}

Autoridade Nacional Palestina

Banco Mundial

Encyclopaedia Britannica

Escritório Das Nações Unidas Para A Coordenação De Assuntos Humanitários

Foundation for Middle East Peace

Heart of Hope

Israel Ministry of Foreign Affairs

Israeli Central Bureau of Statistics

Museu do Apartheid

Nelson Mandela Foundation

Nuclear Threat Initiative

Palestinian Central Bureau of Statistics

Palestinian Academic Society for the Study of International Affairs

South African Institute of Race Relations

The Washington Institute for Near East Policy

Texto recebido em: 13 de Dezembro de 2016 Aprovado em: 24 de Março de 2017 